\title{
COMPARISON OF THE EFFECTS OF ANTIDEPRESSANTS ON COGNITION FUNCTIONS IN PATIENTS OF MAJOR DEPRESSIVE DISORDERS IN TERTIARY CARE HOSPITAL IN HARYANA
}

\author{
SEEMA RANI ${ }^{1}$, NITIKA SINDHU ${ }^{1 *}$, RAHUL SAINI ${ }^{1}$, A.K PANDEY ${ }^{2}$, ARVIND NARWAT ${ }^{1}$, SUNNY GARG $^{2}$ \\ ${ }^{1}$ Department of Pharmacology, Bhagat Phool Singh Government Medical College for Women, Khanpur Kalan, Sonepat, Haryana, India. \\ ${ }^{2}$ Department of Psychiatry, Bhagat Phool Singh Government Medical College for Women, Khanpur Kalan, Sonepat, Haryana, India. \\ Email: nitika.sindhu52@gmail.com
}

Received: 08 December 2020, Revised and Accepted: 20 January 2021

ABSTRACT

Objective: Depression is one of the most common mood disorders. Patients with major depressive disorder (MDD) usually present alterations in various cognitive functions. Several cost-effective interventions have shown favorable recovery and positive outcomes in the care and management of depression. The objective of the study was to compare the effect of fluoxetine (selective serotonin reuptake inhibitors), and venlafaxine (serotoninnorepinephrine reuptake inhibitors) on cognitive functioning in patients with MDD.

Methods: This prospective, single-blinded, randomized, and comparative interventional clinical study was conducted in a tertiary care hospital in Haryana. Fifty-two patients of MDD (ICD-10) were randomly divided into two groups: Group F and Group V, allocated to receive fluoxetine and venlafaxine, respectively. The assessment was done during the enrolment and at the end of the $3^{\text {rd }}, 6^{\text {th }}, 9^{\text {th }}$, and $12^{\text {th }}$ weeks of treatment using the ABCHamilton Depression Rating Scale (HAM-D) and Montreal Cognitive Assessment (MoCA) Scale.

Statistical Analysis Used: The intragroup analysis was performed using repeated measures ANOVA while intergroup analysis was performed using unpaired " $\mathrm{t}$ "-test. $\mathrm{p}<0.05$ was considered statistically significant.

Results: Mean HAM-D score was clinically as well as statistically significant at the end of the $12^{\text {th }}$ week of treatment as compared to baseline in both the groups while on the intergroup comparison, there was no statistically significant difference in both groups. The mean MoCA score was (25 \pm 2.19 ) in Group F and (23.76 \pm 6.97 ) in Group V at the end of the $12^{\text {th }}$ week. On intergroup analysis at the $12^{\text {th }}$ week, a statistically significant improvement in cognitive functions was observed in patients Group F as compared to Group V $(\mathrm{p}<0.05)$.

Conclusions: The study of fluoxetine comparatively better improves cognition functions as compared to venlafaxine.

Keywords: Hamilton depression rating scale, Montreal cognitive assessment scale, Fluoxetine and venlafaxine.

(c) 2021 The Authors. Published by Innovare Academic Sciences Pvt Ltd. This is an open access article under the CC BY license (http://creativecommons.org/ licenses/by/4.0/) DOI: http://dx.doi.org/10.22159/ajpcr.2021v14i3.40467. Journal homepage: https://innovareacademics.in/journals/index.php/ajpcr

\section{INTRODUCTION}

Globally, in 2015, an estimated 322 million people were affected by depression. India is home to an estimated 57 million people $(18 \%$ of the global estimate) affected by depression [1]. Depression is the main cause of illness and disability among the young and middle-aged population. Patients with major depressive disorder (MDD) usually present with alterations in various cognitive functions [2,3]. It often results in impaired functioning, which has an impact on all aspects of an individual's life and family [4]. Depression is largely preventable and treatable. Several cost-effective interventions have shown favorable recovery and positive outcomes in the care and management of depression. The treatment options include non-pharmacological therapies and pharmacological therapies [5]. However, the best results are seen with non-pharmacological therapies in conjunction with pharmacological therapy.

Pharmacotherapy includes monoamine oxidase inhibitors (MAOIs) and tricyclic antidepressants (TCAs), selective serotonin reuptake inhibitors (SSRIs), for example, fluoxetine, serotonin-norepinephrine reuptake inhibitors (SNRIs), for example, venlafaxine. The SSRIs and SNRIs have proven greater efficacy and safety than the TCAs and MAOIs [6]. The efficacy can be measured as changes from baseline or remission on an investigator-rated diagnostic depression scale such as the Hamilton Depression (HAM-D) Rating Scale for depression. The effects of antidepressant medications on cognition are an important, yet surprisingly understudied question. Moreover, the limited literature evaluating this question may be restricted because these evaluations are not typically conducted from a neuropsychological perspective that includes a comprehensive assessment of cognitive domains of executive functioning, attention, concentration, psychomotor speed, memory, and verbal and visuospatial memory, a radical understanding of cognitive effects of antidepressant medications remains unknown. Hence, the present study was aimed at comparing the effect of different antidepressants, fluoxetine, and venlafaxine on cognition functioning in patients with MDD in tertiary care hospital, Haryana.

\section{METHODS}

This prospective, single-blinded randomized, and comparative clinical study was done as per the principles of good clinical practice (ICHGCP) and the Declaration of Helsinki. The study was conducted after obtaining ethical clearance from the institutional ethics committee (IEC). Patients with MDD were screened and selected as per the inclusion and exclusion criteria for this study.

Newly diagnosed patients with severe/major depression (according to ICD-10) [7], of either sex between the age of 18 and 69 years, having a minimum educational qualification up to fifth class were included and those who were having a history of substance abuse and on any other medications, with any other psychiatric illness or any other central nervous system and systemic disorder that are known to affect cognition and psychomotor functions were excluded from the study. A patient information sheet was provided to every eligible subject for the 
study and thereafter a written informed consent was taken from the subjects.

The eligible subjects were randomly divided into two groups, 30 in each group who received one of the following treatments for 12 weeks. Group $\mathrm{F}$ patients received fluoxetine (20-40 mg) and Group V has received venlafaxine (75-150 $\mathrm{mg}$ ) provided from the hospital supply. Starting doses of fluoxetine and venlafaxine were $20 \mathrm{mg}$ and $75 \mathrm{mg}$, respectively. Drug doses may be adjusted depending on the symptoms of patients during subsequent follow-up.

Groups F and V also received Clonazepam $0.5 \mathrm{mg}$ for an initial 2 weeks in addition to studying drugs. It was given to control the symptoms because of the lag period of antidepressants to shows their clinical effects. Therefore, the initial assessment of the patient was done on day 0 , that is, on the day of enrolling the patient, and the subsequent assessment of the patient was done after the clonazepam washes out from the system completely, that is, at the end of $3^{\text {rd }}, 6^{\text {th }}, 9^{\text {th }}$, and $12^{\text {th }}$ weeks. All the subjects were assessed with the ABC version Hamilton Depression Rating Scale (HAM-D) [8] and the Montreal Cognition Assessment Scale (MoCA) [9]

\section{Primary end points}

$A B C$ version $H A M-D$

HAM-D developed by Max Hamilton in 1960 is a multiple item questionnaire used to indicate depression, and as a guide to evaluating recovery. The questionnaire is meant for adults and is employed to rate the severity of their depression. The theoretical score range of the whole HAM-D17 goes from 0 to 52 . For the HAM-D17, a score of $0-7$ is generally accepted to be within the normal range or the patient is in the clinical remission phase, while a score of 20 or higher indicating at least moderate severity of the depression.

\section{Montreal cognitive assessment (MoCA)}

The MoCA is meant as a rapid screening instrument for mild cognitive dysfunction. It contains eight questions that assessed different cognitive domains: attention and concentration, executive functions, memory, language, visuoconstructional skills, conceptual thinking, calculations, and orientation. Each patient was given a maximum of $10 \mathrm{~min}$ to complete the test. MoCA comprises 30 points and the normal score is considered to be 26 and above and it has good reliability for repeated assessment [10].

\section{Statistical analysis}

Data were expressed as mean \pm SEM unless specified otherwise. Both intragroup and intergroup statistical analysis was performed. The intragroup analysis was performed using repeated measures ANOVA while intergroup analysis was performed using unpaired " $t$ " test. $\mathrm{p}<0.05$ was considered statistically significant.

\section{RESULTS}

The demographic profile of the patients in the two study groups was comparable, as shown in Table 1 . The average age in Group F was $32.46 \pm 12.59$ and Group V was $37.23 \pm 11.03$ in years. The total male to female ratio of the patients involved in the study was 1.73:1 (Fig. 1)

Clinical assessment of depression in the Group-F, mean HAM-D score at baseline and $3^{\text {rd }}, 6^{\text {th }}, 9^{\text {th }}$, and $12^{\text {th }}$ weeks was $20.11 \pm 2.51,17.23 \pm 2.91$, $14.30 \pm 4.89,10.57 \pm 3.16$, and $8.30 \pm 2.73$, respectively. In Group V, the mean score was $20.57 \pm 2.74,17.84 \pm 2.96,15.07 \pm 3.24,12 \pm 2.99$, and $9.46 \pm 2.91$, respectively (Table 2). The mean HAM-D score in Group F and Group V at different time intervals is shown in Fig. 2.

On intragroup comparison in both the groups at $3^{\text {rd }}, 6^{\text {th }}, 9^{\text {th }}$, and $12^{\text {th }}$ weeks intervals from the baseline, the results were statistically significant $(\mathrm{p}<0.05)$. However, on intergroup analysis, the mean HAM-D score was compared between Group F and Group V; it was observed that the difference in mean HAM-D score at $3^{\text {rd }}, 6^{\text {th }}, 9^{\text {th }}$, and $12^{\text {th }}$ weeks interval was clinically as well as statistically nonsignificant.
Table 1: Demographic details

\begin{tabular}{lll}
\hline Variable & Group F(n=26) & Group V (n=26) \\
\hline Mean age & $32.46 \pm 12.59$ & $37.23 \pm 11.03$ \\
Gender (M: F) & $1.77: 1$ & $1.7: 1$ \\
\hline
\end{tabular}

Table 2: Intergroup comparison of Hamilton depression rating scale in Group F $(n=26)$ and Group V $(n=26)$

\begin{tabular}{llll}
\hline Time interval & Group F & Group V & p value \\
\hline Baseline & $20.11 \pm 2.51$ & $20.57 \pm 2.74$ & 0.26 \\
$3^{\text {rd }}$ week & $17.23 \pm 2.91$ & $17.84 \pm 2.96$ & 0.22 \\
$6^{\text {th }}$ week & $14.30 \pm 4.89$ & $15.07 \pm 3.24$ & 0.25 \\
$9^{\text {th }}$ week & $10.57 \pm 3.16$ & $12 \pm 2.99$ & 0.50 \\
$12^{\text {th }}$ week & $8.30 \pm 2.73$ & $9.46 \pm 2.91$ & 0.07 \\
\hline
\end{tabular}

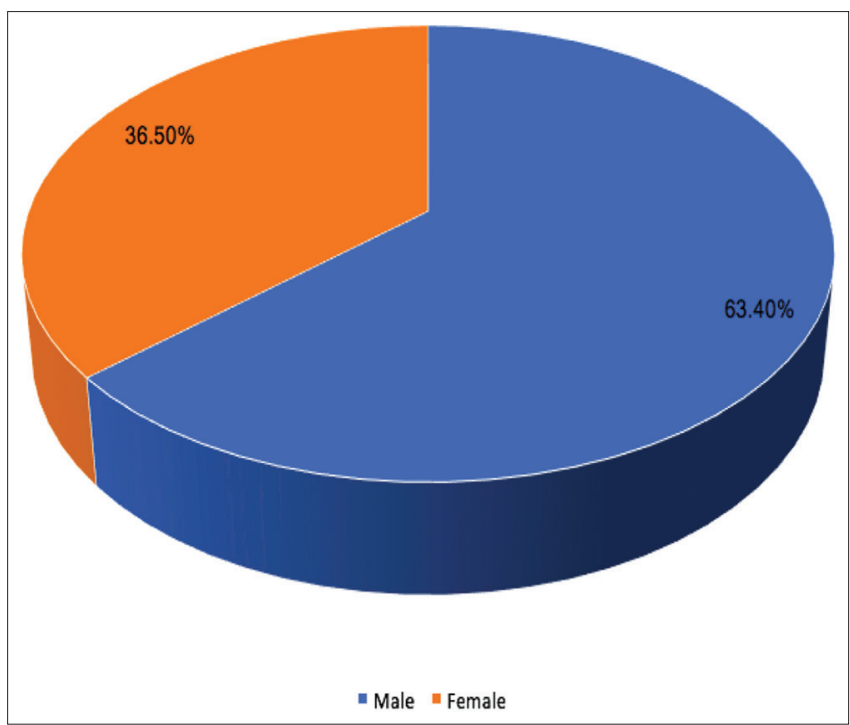

Fig. 1: Pie chart showing gender distribution of major depressive disorder patients

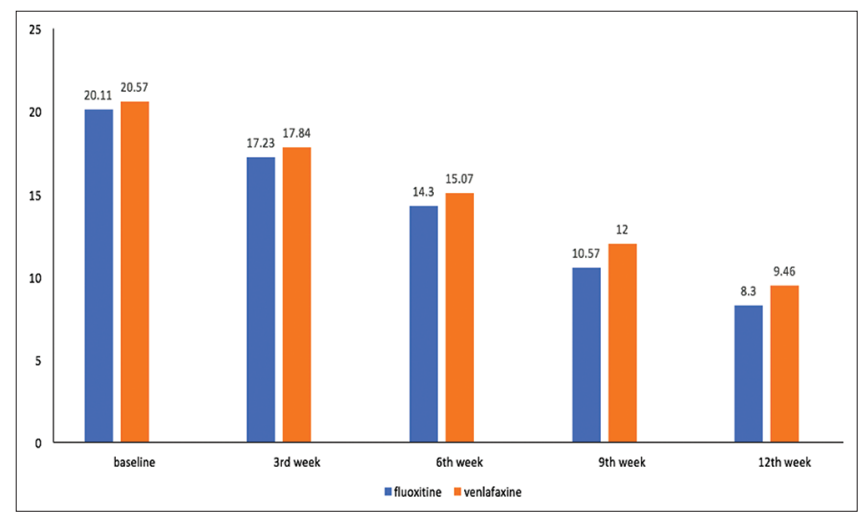

Fig. 2: Intergroup and intragroup comparison of Hamilton depression rating scale score in Group $F$ and Group $V$

Cognitive functions were assessed using MoCA Scale at baseline and the end of $3^{\text {rd }}, 6^{\text {th }}, 9^{\text {th }}$, and $12^{\text {th }}$ weeks MoCA scores in Group F was $17.07 \pm 2.41,19.23 \pm 1.92,21.53 \pm 2.21,23.46 \pm 2.70$, and $25 \pm 2.19$, respectively, and in the Group-V, mean MoCA score was 15.34 \pm 2.52 , $17.73 \pm 2.29,19.76 \pm 2.29,21.88 \pm 2.30$, and 23.76 \pm 6.97 , respectively (Table 3). The mean MoCA score in Group F and Group V at different time intervals is shown in Fig. 3. 
Table 3: Intergroup comparison of Montreal cognitive assessment scale in Group F ( $n=26)$ and Group V $(n=26)$

\begin{tabular}{llll}
\hline Time interval & Group F & Group V & p value \\
\hline Baseline & $17.07 \pm 2.41$ & $15.34 \pm 2.52$ & $0.007^{*}$ \\
$3^{\text {rd }}$ week & $19.23 \pm 1.92$ & $17.73 \pm 2.29$ & 0.006 \\
$6^{\text {th }}$ week & $21.53 \pm 2.21$ & $19.76 \pm 2.29$ & $0.003^{*}$ \\
$9^{\text {th }}$ week & $23.46 \pm 2.70$ & $21.88 \pm 2.30$ & 0.013 \\
$12^{\text {th }}$ week & $25 \pm 2.19$ & $23.76 \pm 6.97$ & 0.029 \\
\hline
\end{tabular}

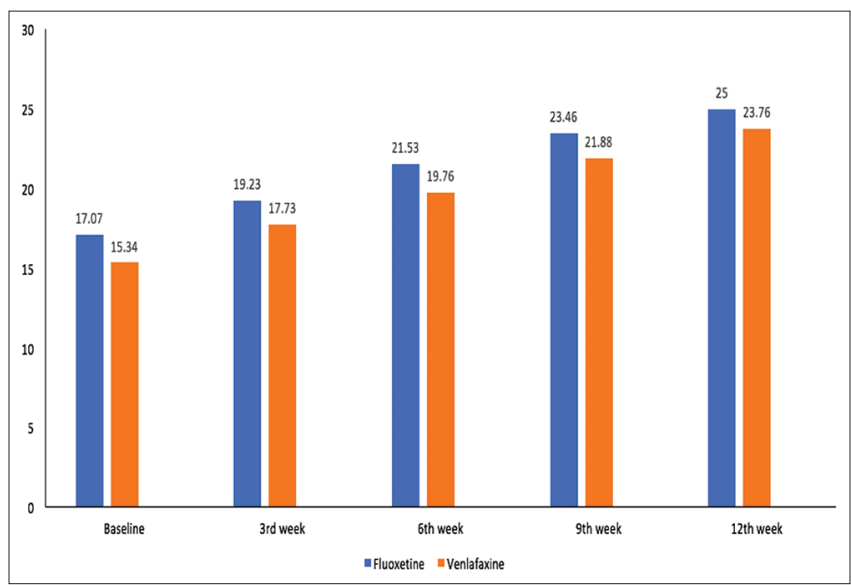

Fig. 3: Intergroup and intragroup comparison of Montreal cognitive assessment score in Group F and Group V

On intragroup comparison in both the groups at $3^{\text {rd }}, 6^{\text {th }}, 9^{\text {th }}$, and $12^{\text {th }}$ weeks intervals from the baseline, the results were statistically significant $(\mathrm{p}<0.05)$. However, on intergroup analysis, the mean MoCA score was compared between Group F and Group V, it was observed that the difference in mean MoCA score at $3^{\text {rd }}, 6^{\text {th }}$, and $9^{\text {th }}$ weeks interval was clinically as well as statistically nonsignificant but at the end of $12^{\text {th }}$ weeks of treatment Group F showed a statistically significant improvement in cognitive functions as compared to Group V $(\mathrm{p}<0.05)$.

\section{DISCUSSION}

The management of depressive patients for improvement of cognitive functions remains an area for never-ending research with better formulations and modalities continuously replacing present ones. Impairment of cognition functions is commonly reported in individuals with MDD. This study was done to evaluate the effect of SSRI and SNRI, that is, fluoxetine $(20-40 \mathrm{mg})$ and venlafaxine $(75-150$ on cognition in patients with MDD. Each study group had 26 patients of either sex between 18 and 69 years was completed the study. The mean age was $32.46 \pm 12.59$ years in Group F, and 37.7 \pm 11.03 years in Group V. The observations of this study showed that there was no statistically significant difference between the ages of patients in both the groups ( $p>0.05$ ). In this study, there were approximately $60 \%$ males and $40 \%$ females. The overall male to female patient ratio was 1.73:1. Jaykaran et al. [11] and Ghodke et al. [10] conducted a similar study which showed a demographic profile of having $58 \%$ of male, $45 \%$ of female and $55 \%$ of male, $45 \%$ of female, respectively. However, some studies do not corelate with this male-female ratio. It completely depends on the area in which the study is conducted rural and urban due to which the male-female ratio differs.

HAM-D was taken used to evaluate the severity of depression and also to evaluate recovery from depression. In the present study, the mean HAM-D score was compared between Group F and Group V at baseline, end of $3^{\text {rd }}, 6^{\text {th }}, 9^{\text {th }}$, and $12^{\text {th }}$ weeks. In Group-F, mean HAM-D scores at the different intervals were $20.11 \pm 2.51,17.23 \pm 2.91,14.30 \pm 4.89$, $10.57 \pm 3.16$, and $8.30 \pm 2.73$, and in the Group $-\mathrm{V}$, mean HAM-D scores were $20.57 \pm 2.74,17.84 \pm 2.96,15.07 \pm 3.24,12 \pm 2.99$, and $9.46 \pm 2.91$. Both drugs were found to be equally efficacious. The patients treated with fluoxetine and venlafaxine showed a significant reduction in scores at the end of every follow-up as compared to the baseline. On intergroup analysis, the mean HAM-D score was compared between Group F and Group V; it was observed that the difference in mean HAM-D score at $3^{\text {rd }}, 6^{\text {th }}, 9^{\text {th }}$, and $12^{\text {th }}$ weeks interval was clinically as well as statistically nonsignificant. A similar study was conducted by Mendhe et al. [12], study revealed that on comparing the efficacy of the antidepressants, all the groups showed a significant reduction in mean scores at the end of the $1^{\text {st }}$ month and $3^{\text {rd }}$ month as compared to the baseline values. However, no statistically significant difference was observed at the end of 3 months of treatment among the different groups. Wagner et al. [13] observed that the HAM-D score was statistically significant in an 8-week study while comparing escitalopram, venlafaxine, and lithium. Few other studies showed similar results in the HAM-D score while comparing different antidepressants [14-17]. In this study, we also observed that both the drugs are efficacious in improving the symptoms of depression from 3 weeks onward with progressive improvement till the end of the study. Thus, both the antidepressant drugs were well tolerated and equally efficacious in improving symptoms of depression.

Cognitive functions were assessed using the MoCA. The difference in the values between baseline and at the end of the study period was calculated and compared. In our study, the mean score of MoCA in Group $\mathrm{F}$ at different interval, that is, at the end of $3^{\text {rd }}, 6^{\text {th }}, 9^{\text {th }}$, and $12^{\text {th }}$ weeks from the baseline $(17.07 \pm 2.4)$ was $19.23 \pm 1.92,21.53 \pm 2.21,23.46 \pm 2.70$, and $25 \pm 2.19$, respectively. In Group V, the mean score of MoCA at different interval, that is, at the end of $3^{\text {rd }}, 6^{\text {th }}, 9^{\text {th }}$, and $12^{\text {th }}$ weeks from the baseline $(15.34 \pm 2.52)$ was $17.73 \pm 2.29,19.76 \pm 2.29,21.88 \pm 2.30$, and $23.76 \pm 6.97$, respectively. Up to my knowledge, no previous study was found using MoCA for cognitive assessment in different classes of antidepressants but studies were there which showed an effect on cognition in patients of MDD. The present study used this scale as it was assessed several cognitive domains at first time and was a more sensitive tool to assess cognition, especially mild cognition deficit. We observed clinically as well as statistically improvement in the mean MoCA scores at the end of $3^{\text {rd }}, 6^{\text {th }}, 9^{\text {th }}$, and $12^{\text {th }}$ weeks from the baseline in both the groups at a different time interval, that is, $\mathrm{p}<0.05$. On intergroup analysis, the mean MoCA score at $3^{\text {rd }}, 6^{\text {th }}$, and $9^{\text {th }}$ weeks interval was clinically as well as statistically nonsignificant but at the end of the $12^{\text {th }}$ week of treatment Group F showed a statistically significant improvement in cognitive functions as compared to Group V $(\mathrm{p}<0.05)$.

The strengths of the present study were that we used standard, validated scales during our study for assessing cognition functioning in patients of MDD. To the best of our knowledge, no studies had assessed Cognition using Montreal Cognitive scale which was more sensitive than Mini-Mental Scale $[18,19]$ but some studies showed the impact of depressive symptomatology on the MoCA as a cognitive screening tool [20]. In our study, it is used for the first time to compare the effect of different classes of antidepressants on cognitive functioning and with a different mechanism of action which helps us to know more about the role of neurotransmitters in cognition improvement. However, our study had some limitations also. The number of patients enrolled in each group was less. A strict inclusion criterion for patients suffering only from endogenous depression not associated with any other comorbidity and concomitant medication was excluded from the study. Second, the duration of the study was short, and we could not follow the patients until the complete remission of the disease. Significant limitations were the heterogeneity of results

However, the importance of the present study cannot be undermined. Studies are available which show the effect of antidepressants on cognitive functions but most of these studies are single-dose studies, and studies of the same class of antidepressants [21].

\section{CONCLUSION}

The findings of this study provide insight into the fact that antidepressant medications affect several areas of cognition, 
including processing speed, attention, and some areas of learning and memory. Our study suggests that both the SSRI and SNRI classes of antidepressant drugs are equally effective in the treatment of depression when compared to baseline along with improving cognition functioning. Fluoxetine significantly improves cognition functions as compared to venlafaxine.

\section{ACKNOWLEDGMENT}

Special thanks to Mr. Sanjeet Singh from Community Medicine Department for helping us with statistics.

\section{FUNDING}

No funding sources.

\section{CONFLICT OF INTEREST}

No.

\section{REFERENCES}

1. James SL, Abate D, Abate KH, Abay SM, Abbafati C, Abbasi N, et al. Global, regional, and national incidence, prevalence, and years lived with disability for 354 diseases and injuries for 195 countries and territories, 1990-2017: A systematic analysis for the global burden of disease study 2017. Lancet 2018;392:1789-858.

2. Austin MP, Mitchell P, Goodwin GM. Cognitive deficits in depression: Possible implications for functional neuropathology. Br J Psychiatry 2001;178:200.

3. Rogers MA, Kasai K, Koji M, Fukuda R, Iwanami A, Nakagome K, et al. Executive and prefrontal dysfunction in unipolar depression: A review of neuropsychological and imaging evidence. Neurosci Res 2004;50:1-11

4. Saxena S, Krug E, editors. Preventing Suicide: A Global Imperative. Geneva: World Health Organization; 2014. p. 1-92.

5. World Health Organisation. International Statistical Classification of Diseases and Related Health Problems $10^{\text {th }}$ Revision (ICD-10). Geneva: World Health Organization; 2016.

6. O'Donnell JM, Shelton RC. Drug therapy of depression and anxiety disorders. In: Brunton LL, editors. Goodman and Gilman's the Pharmacological Basis of Therapeutics. 12th ed. New York: p. 397-415.

7. World Health Organisation. International Classification of Diseases (ICD) 10. Depressive Episode. Geneva: World Health Organisation; F32.9.
8. Hamilton M. A rating scale for depression. J Neurol Neurosurg Psychiatry 1960;23:56-62

9. Nasreddine ZS, Phillips NA, Bedirian V. The montreal cognitive assessment, MoCA: A brief screening tool for mild cognitive impairment. J Am Geriatr Soc 2005;53:695-9.

10. Ghodke VB, Mohanty IR, Ghildiyal R, Shounak A, Deshmukh YA, et al. Effect of selective serotonin reuptake inhibitors on psychomotor function in patients of depression: A comparative study of sertraline and fluoxetine. J Med Sci 2015;2:72-7.

11. Jaykaran, Bhardwaj P, Kantharia N D, Yadav P, Panwar A. Effect of fluoxetine on some cognitive functions of patients of depression. Indian J Psychol Med 2009;31:24-9.

12. Mendhe PP, Shah SP, Desai MK, Parikh MN. Comparison of effect of antidepressants on psychomotor functions. Indian J Psychol Med 2017;39:69-75.

13. Wagner S, Helmreich I, Wollschlager D, Meyer K, Kaaden S, Reiff J, et al. Early improvement of executive test performance during antidepressant treatment predicts treatment outcome in patients with major depressive disorder. PLoS One 2018;13:1-13.

14. Ixchel HG, Esteve GF, Daniel HG, Joan GO, Erika HC, Jorge EH. Effects of selective serotonin reuptake and dual serotonergicnoradrenergic reuptake treatments on memory and mental processing speed in patients with major depressive disorder. J Psychiatric Res 2009;43:855-63.

15. Chang HH, Lee IH, Gean PW, Lee SY, Chi MH, Yang YK, et al. Treatment response and cognitive impairment in major depression: Association with C-reactive protein. Brain Behav Immun 2012;26:90-5.

16. Halahakoon DC, Roiser JP. Cognitive impairment in depression and its (non-)response to antidepressant treatment. Evid Based Mental Health 2016;19:e23

17. Shilyansky C, Williams LM, Gyurak A. Effect of antidepressant treatment on cognitive impairments associated with depression: A randomised longitudinal study. Lancet Psychiatry 2016;3:425-35.

18. Folstein MF, Folstein SE, McHugh PR. "Mini-mentalstate" a practical method for grading the cognitive state of patients for the clinician. $\mathrm{J}$ Psychiatr Res 1975;2:189-98.

19. Donovan M, Mario C, Laurie G, Susan R, Chris T, Michael ET. Psychiatric rating scales. Handb Clin Neurol 2012;106:227-37.

20. Blair M, Coleman K, Jesso S, Jodoin VD, Smolewska K, Warriner E, et al. Depressive symptoms negatively impact montreal cognitive assessment performance: A memory clinic experience. Can J Neurol Sci 2016;43:513-7.

21. Mendhe PP, Shah SP, Desai MK, Parikh MN. Comparison of effect of antidepressants on psychomotor functions. Indian J Psychol Med 2017;39:69-75. 


\section{Hamilton Depression Rating Scale (HAM-D) also HDRS or HRSD}

PatientName: Date:

Instructions: For each item select the "cue" which best characterizes the patient during the past week.

1. Depressed Mood (sadness, hopeless, helpless, and worthless)

0 Absent

1 These feeling states indicated only on questioning

2 These feeling states spontaneously reported verbally

3 Communicates feeling states nonverbally, i.e., through facial expression, posture, voice and tendency to weep

4 Patient reports VIRTUALLY ONLY these feeling states in his spontaneous verbal and nonverbal communication

2. Feelings of Guilt

0 Absent

1 Self-reproach, feels he has let people down

2 Ideas of guilt or rumination over past errors or sinful deeds

3 Present illnesses are a punishment. Delusions of guilt

4 Hears accusatory or denunciatory voices and/or experiences threatening visual hallucinations

3. Suicide

0 Absent

1 Feels life is not worth living

2 Wishes he were dead or any thoughts of possible death to self

3 Suicide ideas or gesture

4 Attempts at suicide (any serious attempt rates 4 )

4. Insomnia - Early

0 No difficulty falling asleep

1 Complains of occasional difficulty falling asleep i.e., more than $1 / 2 \mathrm{~h}$

2 Complains of nightly difficulty falling asleep

5. Insomnia - Middle

0 No difficulty

1 Patient complains of being restless and disturbed during the night

2 Waking during the night - any getting out of bed rates 2 (except for purposes of voiding)
9. Agitation

0 None

1 "Playing with" hand, hair, etc.

2 Hand-wringing, nail-biting, biting of

lips

10. Anxiety - Psychic

0 No difficulty

1 Subjective tension and irritability

2 Worrying about minor matters

3 Apprehensive attitude apparent in face or speech

4 Fears expressed without questioning

11. Anxiety - Somatic

0 Absent

1 Mild

2 Moderate

3 Severe

4 Incapacitating

12. Somatic Symptoms - Gastrointestinal 0 None

1 Loss of appetite but eating without staff encouragement.

2 Difficulty eating without staff urging. Requests or requires laxatives or medications for bowels or medication for G.I. symptoms.

13. Somatic Symptoms - General

0 None

1 Heaviness in limbs, back or head, backaches, headache, muscle aches, loss of energy and fatigability

2 Any clear-cut symptom rates 2

14. Genital Symptoms

0 Absent

1 Mild

2 Severe
Physiological concomitants of anxiety such as:

Gastrointestinal - dry mouth, wind, indigestion,

diarrhea, cramps, belching

Cardiovascular - palpitations,

headaches

Respiratory - hyperventilation,

sighing

Urinary frequency

Sweating
0 Not ascertained symptoms such as: loss of libido, menstrual disturbances 
6. Insomnia - Late

0 No difficulty

1 Waking in early hours of the morning but goes back to sleep

2 Unable to fall asleep again if gets out of bed

7. Work and Activities

0 No difficulty

1 Thoughts and feelings of incapacity, fatigue or weakness related to activities; work or hobbies

2 Loss of interest in activity; hobbies or work - either directly reported by patient, or indirect in listlessness, indecision and vacillation (feels he has to push self to work or activities)

3 Decrease in actual time spent in activities or decrease in productivity. In hospital, rate 3 if patient does not spend at least $3 \mathrm{~h}$ a day in activities (hospital job or hobbies) exclusive of ward chores.

4 Stopped working because of present illness. In hospital, rate 4 if patient engages in no activities except ward chores, or if patient fails to perform ward chores unassisted.

8. Retardation (slowness of thought and speech; impaired ability to concentrate; decreased motor activity)

0 Normal speech and thought

1 Slight retardation at interview

2 Obvious retardation at interview

3 Interview difficult

4 Complete stupor

\section{Hypochondriasis}

0 Not present

1 Self-absorption (bodily)

2 Preoccupation with health

3 Frequent complaints, requests for help,

etc.

4 Hypochondriacally delusions

16. Loss of Weight

A. When Rating by History:

0 No weight loss

1 Probable weight loss associated with present illness

2 Definite (according to patient) weight loss

Changes are Measured:

0 Less than $1 \mathrm{lb}$. weight loss in week

$1>1 \mathrm{lb}$. weight loss in week

$2>2 \mathrm{lb}$. weight loss in week

17. Insight

0 Acknowledges being depressed and ill

1 Acknowledges illness but attributes cause to bad food, climate, overwork, virus, need for rest, etc.

2 Denies being ill at all

Total Score

$A B C$-version of the Hamilton Depression Scale (HAM-D)

The pure depression picture

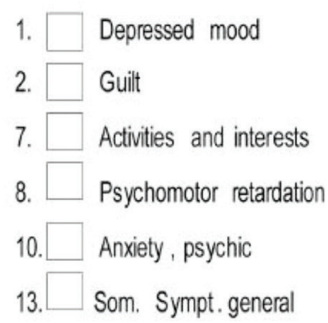

(A) $\mathrm{HAM} \cdot \mathrm{D}_{6}$ Total score:
(A)

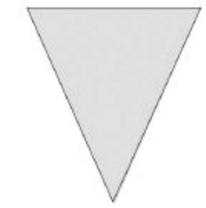

(C)

The suicide risk behaviour

3.

Suicidal thoughts

16. $\square$ Insight
The stress -related arausal

(B) 4. Insomnia : initial

5. $\square$ Insomnia : middle

6. I Insomnia : late

9. Psychomotor agitation

11. $\square$ Anxiety, somatic

12. Gastrointestinal sympt.

14. $\square$ Sexual disturbances

15. $\square$ Hypochondriasis

17. Weightloss

(C) $\begin{aligned} & \text { HAM-D } \\ & \text { Total score: }\end{aligned} \quad$ (B)
Total score:

HAM-D ${ }_{17}$ Total score: $(A+B+C)$ 


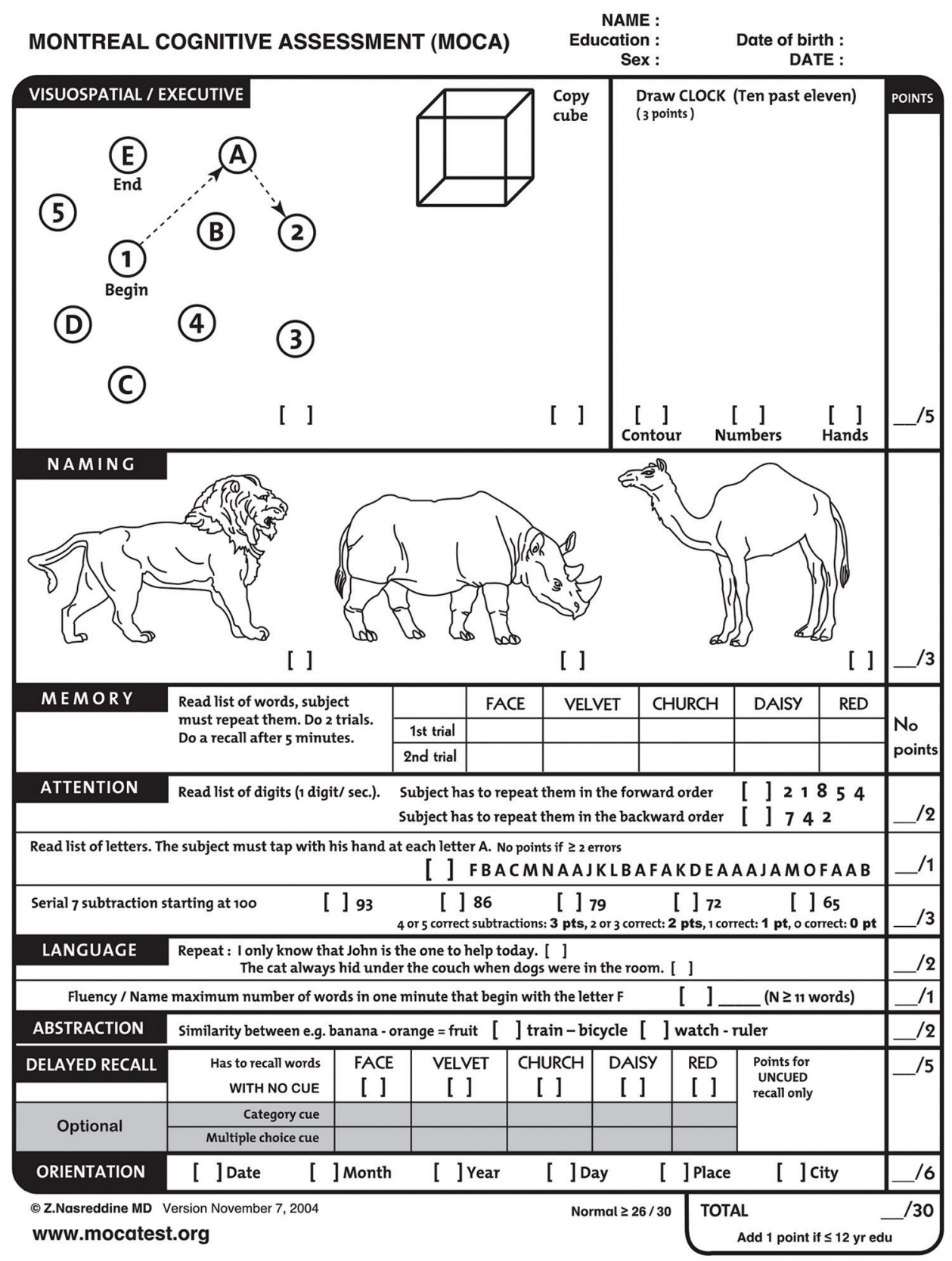

